\title{
Low Cost Synthesis of Single Walled Carbon Nanotubes from Coal Tar Using Arc Discharge Method
}

\author{
Mainak Saha \\ Department of Metallurgical and Materials Engineering , Naitional Institute of Technology(NIT), \\ Durgapur,India
}

\begin{abstract}
There are various methods such as arc discharge, laser ablation, chemical vapour deposition (CVD), template-directed synthesis for the growth of CNTs in the presence of catalyst particles. The production of carbon nanotubes in large quantities is possible with inexpensive coal as the starting carbon source by the arc discharge technique. It is found that a large amount of carbon nanotubes of good quality can be obtained in the cathode deposits in which carbon nanotubes are present in nest-like bundles. For more than two decades, now, there has been extensive research on the production of carbon nanotubes (CNT) and optimization of its manufacture for the industrial applications. It is believed that they are the strong enough but most flexible materials known to mankind. They have potential to take part in new nanofabricated materials. It is known that, carbon nanotubes could behave as the ultimate one-dimensional material with remarkable mechanical properties. Moreover, carbon nanotubes exhibit strong electrical and thermal conducting properties. This paper primarily concentrates on the optimising such parameters related to the mass production of the product. It has been shown through Simplex process that based on the cost of the SWNT obtained by the arc discharge technique, the voltage and the current should lie in the range of $30-42 \mathrm{~V}$ and 49 - $66 \mathrm{~A}$ respectively. Any combination above the given values will lead to a power consumption cost beyond the final product cost, in turn leading to infeasibility of the process. Strong expectations exist for future use of carbon nanotubes as composite materials in a large number of industries. Production cost and control of the purity and properties of such materials will influence the impacts nanotubes on the chemical, computer and construction industries. Coal properties in this case are also important. Weak bonds and mineral matter in the coal play an important role in the formation of the nanotubes.
\end{abstract}

Keywords: Coal tar; Carbon Nanotubes; SWCNT; Simplex; Optimization

\section{Introduction}

In 1985, Drexler.et.al proposed a molecular bearing consisting of two graphitic nanotubes of different diameter, which are concentrically arranged. It was a virtual operation inside a computer. This dream, however, has become more realistic by the discovery of carbon nanotubes. There had been revolutionizing researches on the pro- duction of Carbon Nanotubes from last twenty years and optimising its manufacture for the industrial applications. It has been thought that they are the strongest but most agile materials known to humankind, and thus have potential to take part in new nanofabricated materials as additives. It has been shown that carbon nanotubes could behave as the ultimate one-dimensional material with remarkable mechanical properties. Carbon nanotubes exhibit strong electrical and thermal conducting properties. Study of the past researches on the production of carbon nanotubes from coal revealed that most of the researches concentrate on producing CNT by arcing electrodes, produced separately by mixing the crushed coal with coal tar followed by molding process. However, the only process till date that has shown a positive adaptation to direct coal application is thermal plasma jet technique. With the extensive research in the production of the Carbon Nanotubes, the requirement of optimising the process parameters are realised. This paper concentrates on the optimising such parameters related to the mass production of the product. It has been found through calculation that the only determining parameter in the arc discharge technique is the power of the equipment, in terms of voltage and current, and it is seen that on optimisation of these parameters, the cost of the process reduces drastically.

\section{Method of synthesizing SWCNTs from non-metallurgical grade coal fines and coal tar through arc discharge technique}

There are various methods such as arc discharge, laser ablation, chemical vapour deposition (CVD), template-directed synthesis and the use of the growth of CNTs in the pre- sence of catalyst particles.Special ambient gas is re quired for the fabrication of SWCNTs, in order to prevent the oxidation of carbon at high temperature. The production of carbon nanotubes in large quantities and other nanomaterials as by-products is possible with inexpensive coal as the starting carbon source by the arc discharge technique. It has been found that a large amount of carbon nanotubes of good quality can be obtained in the cathode deposits in which carbon nanotubes are present in nest-like bundles which is determined using Scanning Electron Microscope(SEM) and 
Selected Area Diffraction Pattern(SADP) in high resolution Transmission Electron Microscopy(HRTEM). Compared to other methods, the arc discharge is the simplest, cheapest and easy to implement and it has been used because of its potential merits to make a massive production. The mineral matter in raw coals may also play an important part in the formation process of carbon nanotubes. The proposed procedure for carrying out arc deposition of SWCNTs from non-metallurgical grade coal fines and coal tar which is obtained as one of the by-products from a steel plant are as follows. the coal is crushed and sieved with $150 \mu \mathrm{m}$ mesh. Then it is mixed with coal tar and molded to form coal rods used for anode with a graphite cathode for the arc discharge process. Iron mesh wire is used between electrodes and it is interestingly observed through TEM formation of carbonaceous matter is found to occur on wire mesh. Coal or coal-derived carbons show macromolecular structures rather than the lattice structure of graphite. In their chemical structures there exist many weak binding linkages between carbon polymeric units such as polymerized aryl structures. In the fast paralyses process under arc plasma conditions, these weak linkages will be rather easily to release a variety of reactive fragments of hydrocarbon molecules such as alkynes and aromatic species. In place of heavy hydrocarbons, pure compound, toluene may be used as the pure substrate to establish the reaction system for the production of carbon nanotubes. Toluene is fed by a mist-spray feeding system with a carrier gas as 9:1 mixture of nitrogen and hydrogen at $100 \mathrm{ml} / \mathrm{min}$, and following the reaction at $750^{\circ} \mathrm{C}$ catalysed by $9.8 \%$ (by weight) ferrocene, Carbon nanotubes are found in the carbonaceous product deposited on inner wall of a quartz tube and at the exit of the tube. The product is observed by scanning electron microscopy and analyzed by temperature programmed oxidation experiments to identify the presence of carbon nanotubes. Based on the reaction system and reaction conditions with toluene, the production of nanotubes is examined by using heavy hydrocarbons such as asphaltene and maltene fractions from natural asphalt. Under selected reaction conditions including the reaction temperature and the amount of the catalyst, carbon nanotubes with a diameter of $30-60 \mathrm{~nm}$ are found.

\section{Optimisation of voltage and current used in the SWCNT synthesis using arc plasma deposition process}

It is known that Voltage and Current constitute the Power requirements for an electrically operated machine. Same in the case of the production of CNT from the arc discharge method, the electrical power signifies the characteristics of the arc that is generated between the two electrodes, in this case, one coal-based and the other, graphite. For the optimisation process, the total cost of the input materials must be lesser than that of the output product.

\begin{tabular}{|c|c|c|c|c|c|c|c|}
\hline \multirow[t]{2}{*}{ Field/Co. } & \multicolumn{7}{|c|}{ Cost of grades of coal in rupees/tonne } \\
\hline & $\mathrm{A}$ & B & & & & & \\
\hline ECL & 369 & 3590 & 1680 & 1350 & 1010 & 790 & 560 \\
\hline ECL/ Mugma & 369 & 3590 & 1950 & 1610 & 1290 & 960 & 620 \\
\hline ECL/Rajmahal & - & - & - & - & 1330 & 1130 & 910 \\
\hline BCCL & 369 & 3590 & 1630 & 1350 & 1080 & 860 & 610 \\
\hline $\mathrm{CCL}$ & 369 & 3590 & 1590 & 1300 & 1030 & 820 & 590 \\
\hline $\mathrm{NCL}$ & 369 & 3590 & 1430 & 1200 & 960 & 750 & 560 \\
\hline SECL & 369 & 3590 & 1370 & 1140 & 950 & 740 & 560 \\
\hline $\mathrm{MCL}$ & 369 & 3590 & 1370 & 1140 & 950 & 740 & 560 \\
\hline
\end{tabular}

(A-Graphite/high quality anthracite; B-Anthracite (C:H > 30); C-Anthracite (C:H 26 - 30); D-Semianthracite; E-Semi-bituminous; F- Bituminous; G-Low quality bituminous).

\section{Basic price of run of mine non-long-flame non- coking coal} (Courtesy: Coal India Ltd)

\begin{tabular}{|c|c|c|c|c|}
\hline \multirow[t]{2}{*}{ Package (gram) } & \multicolumn{3}{|c|}{ SWNT } & WNT \\
\hline & $\begin{array}{c}\mathrm{P} \\
\text { ur } \\
\text { it } \\
\mathrm{y}( \\
\$)\end{array}$ & $\begin{array}{c}\text { Arc } \mathrm{CNT}^{*} \\
(\$)\end{array}$ & High purity* $(\$)$ & \\
\hline 1 & 210 & 83 & 210 & \\
\hline 10 & 1600 & 700 & 1600 & \\
\hline 50 & 6850 & 3050 & 6850 & \\
\hline 100 & 12400 & 5500 & 12400 & \\
\hline 500 & Call & Call & Call & \\
\hline 1000 & Call & Call & Call & \\
\hline
\end{tabular}




\section{Carbon nanotube price list}

*The High Purity CNT (more than 90\% pure) is not achievable by Arc Discharge Method, as per different researches, and thus the cost of the Arc CNT, made from Arc Discharge Method, is always less than the former. However, DWNTs are not the common by-product from the Arc Discharge Method.

\section{(Courtesy: Coal India Ltd)}

The rate of anode feed in the experiment is taken to be $10 \mathrm{~mm}$ for $2 \mathrm{hrs}$. The length of the electrode in the ex- periment is $75 \mathrm{~mm}$. So, the total experiment time equals $15 \mathrm{hrs}$. For that time the 45 units of electricity is con- sumed $(1 \mathrm{KWhr}=1$ unit of consumed electricity). As per the regulations of Calcutta Electricity Supply Corporation (CESC), the rate is Rs.2.7/unit for the first 25 units consumed, then at the rate of Rs.3.3/unit for the next 35 units. Therefore, Total cost $=25 * 2.7+20 * 3.3=$ Rs.133.5 So, the total input cost for the production of CNT is Rs.133.5 (neglecting the cost of coal as too small as compared to the power consumption cost) .The amount of CNT produced in experiment is about $20 \mathrm{mg}$. The cost above is given in $\$$, so we consider $1 \$=$ Rs 50 and the package unit is in grams. Thus, the total cost comes to be $20 * 83 * 50 / 1000=\mathrm{Rs} 83$. Therefore, it can be understood that as the input cost is greater than the output cost, optimisation is essential in this case. The coalbased electrode specifications for the arc dis- charge process are found from the experimental works in the past. With the aim of the maximum cost involved in the production of the coal-based electrode, the electrode with maximum volume is selected, as it is the electrode that involves the maximum amount of coal and thus the cost. Out of the several independent researches the specification of diameter $10 \mathrm{~mm}$ and length $200 \mathrm{~mm}$ is chosen as it gives the maximum volume as compared to the other electrodes in the other researches.

Therefore, electrode volume $=(3.14 / 4) * 100 * 200=15707$ cubic $\mathrm{mm}$

Bank density of coal is $1346 \mathrm{~kg} /$ cubic metre

So, Bank Weight of the powdered coal used $=1346 * 1.57 * 10^{\wedge}-5=0.021 \mathrm{~kg}$

Maximum Cost of the coal is taken to be Rs. $3.5 / \mathrm{kg}$

Therefore, Cost of the coal used $=3.5 \times 0.021=$ Rs 0.073

The cost of power is to be calculated next. In a typical experiment, the current was taken to be $100 \mathrm{~A}$ and the voltage was taken to be $36 \mathrm{~V}$.

Therefore, Power $=V \times I=30 \times 100=3000 \mathrm{~W}=3 \mathrm{KW}$

Power $(\mathrm{P})=I V$

$\log P=\log V+\log \mathrm{I}$

Taking, $\log P=x 1 ; \log V=x 2 ; \log I=x 3$

In all the experiments minimum voltage and current are taken as $30 \mathrm{~V}$ and 50 A respectively.

$$
\mathrm{V}>=30, \mathrm{I}>=50
$$

$\log \mathrm{V}>=1.47, \log I>=1.69$

Therefore, $\mathrm{x} 1=\mathrm{x} 2+\mathrm{x} 3, \mathrm{x} 2>=1.47 ; \mathrm{x} 3>=1.69$

Considering the power consumption rate as Rs $2.7 /$ unit,

The total power can be calculated as $15 \times 2.7 \times P=40.5 P$

For optimum result, $40.5 \mathrm{P}<=83$

implies, $\mathrm{P}<=2050 \mathrm{~W}$

or, $\log \mathrm{P}<=3.31$

Applying Simplex Algorithm,

$$
\min x 1=x 2+x 3
$$

$x 2+x 3=3.31$

$\mathrm{x} 2=1.47$

$\mathrm{x} 3=1.69$

The area enclosed by the three constraint lines gives the range of feasibility of the variables. 


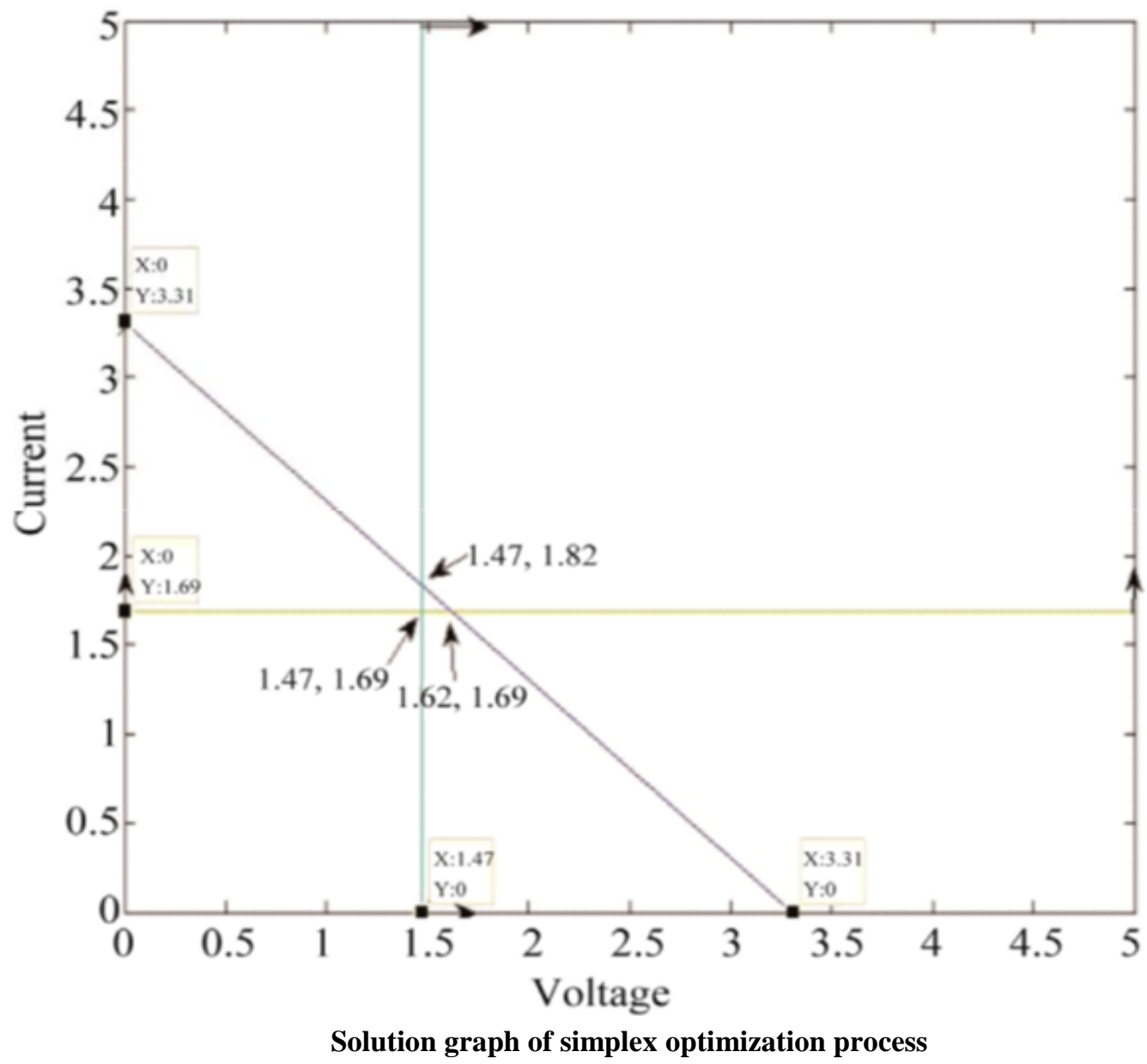

$\operatorname{Max} \times 2=1.62$

$\operatorname{Max} \times 3=1.82$

$\mathrm{V}=41.68 \mathrm{~V}$

$\mathrm{I}=66.07 \mathrm{~A}$

\section{Summary and Conclusions}

An optimisation of the main process parameters i.e. voltage and current, pertaining to the arc discharge process discussed in the paper. The result focuses on the feasible and optimum range of the parameters, based on the cost of the SWNT obtained as the product. It can be certainly perceived through calculation that if the voltage or the current cross the optimal range, the power consumption is increased and thus, the input cost is aggravated resulting in infeasibility of the production line. However, still more scopes remain, as the major assumptions viz. the cost of power consumption is only confined to the unit power consumption cost fixed by CESC, can be made universal by programming the algorithm mentioned above, and a detailed analysis of the optimization by various other processes may lead to many valuable information in this virgin field.

\section{Acknowledgement}

The author will like to expression for the support of the department of Metallurgical and Materials Engineering, NIT DURGAPUR

\section{References}

[1]. J. S. Qiu, Z. Y. Wang, Z. B. Zhao and T. H. Wang.et.al, "Synthesis of Double-Walled Carbon Nanotubes from Coal in HydrogenFree Atmosphere," Fuel, Vol. 86, No. 1-2, 2007, pp. 282-286. doi:10.1016/j.fuel.2006.05.024

[2]. J. S. Qiu, Y. F. Li, Y. P. Wang and W. Li, "Production of Carbon Nanotubes from Coal," Fuel Processing Technology, Vol. 85, No. 15, 2004, pp. 1663-1670. doi:10.1016/j.fuproc.2003.12.010

[3]. K. Kidena, Y. Kamiyama and M. Nomura, "A Possibility of the Production of Carbon Nanotubes from Heavy Hy- drocarbons," Fuel Processing Technology, Vol. 89, No. 4, 2008, pp. 449-454. doi:10.1016/j.fuproc.2007.11.021

[4]. J. L. Yu, J. Lucas, V. Strezov and T. Wall, "Coal and Carbon Nanotube Production," Fuel, Vol. 82, No. 15-17, 2003, pp. 20252032. doi:10.1016/S0016-2361(03)00189-3

[5]. M. A. Wilson, H. K. Patney and J. Kalman, "New Developments in Formation of Nanotubes from Coal," Fuel, Vol. 81, No. 1, 2002, pp. 5-14. doi:10.1016/S0016-2361(00)00192-7 
[6]. K. A. Williams, M. Tachibana, J. L. Allen, L. Grigorian, S. C. Cheng, S. L. Fang, G. U. Sumanasekera, A. L. Loper, J. H. Williams and P. C. Eklund, "Single-wall Carbon Nanotubes from Coal," Chemical Physics Letters, Vol. 310, No. 1-2, 1999, pp. 31-37. doi:10.1016/S0009-2614(99)00725-3

[7]. M. S. Krishnan “Classification of Coal,” Geological Survey of India, Vol. 4, No.3, 1940, p. 552

[8]. http://www.helixmaterial.com/Ordering.html

[9]. Y. Y. Tsai, J. S. Su, C. Y. Su, “A Novel Method to Pro- duce Carbon Nanotubes Using EDM Process,” International Journal of Machine Tools \& Manufacture, Vol. 48, No. 15, 2008, pp. 1653-1657. doi:10.1016/j.ijmachtools.2008.07.005 